presented the results of observations on the number of recognisable steps between white and the spectral colours. There are fewer steps between green and white than between either red or blue and white. There are about an equal number of steps between either red or blue and white. This result agrees with the appearance that green has of being a less 'intense' colour than red or blue.

Prof. H. Hartridge described colour perception in an ivory white light formed by removing all the rays less than $5300 \mathrm{~A}$. and some of the red. By such a light, it is possible to recognise pigmentary colours, but yellows are too pale, blues too dark, and purples too red. Ishihara's tests can be passed by a normal individual in such a light. These results indicate that the receptors for blue are probably stimulated by wave-lengths other than those less than $5300 \mathrm{~A}$.

Prof. H. Pieron's paper dealt with the time necessary for the production of colour by stimuli of short duration. For red the time is $95 \sigma$, for green $105 \sigma$, and for blue $120 \sigma$, thus showing the slower response for receptors for blue.

There were five papers which dealt with the problems of interpretation of visual stimuli. Dr. L. F. Richardson has obtained estimates of the relative amount of red in a given sample of colour, and finds that different individuals show an agreement between their estimates of the relative proportions of red and white in the mixture.

Prof. F. C. Bartlett sent in a paper dealing with the visual perception of depth; and $\mathrm{Mr}$. H. Bannister offered an explanation of Pulfrich's pendulum experiment. Prof. Koffka described the phenomena concerned with contrast in the black-white series, and based a general theory of vision on the results.

Dr. R. A. Granit enlarged upon the significance of the synapses in the retina in relation to the path of the impulses proceeding through the retina to reach the optic nerve cells and fibres.

By the system of limiting each speaker to eight minutes, all the papers were disposed of in time to allow of discussion. As the authors did not reply to criticisms, we must await the publication of the whole discussion in order to know the final decision on some points. It might have been better if the papers had been grouped under subjects, though that is almost impossible, because so many of the subjects overlap, and until the papers have been read it is not easy to know under which subject to classify them.

Amongst the points brought out during the discussion are the following. It seems clear that vision is to be explained on a trichromatic basis. The actual wave-lengths that stimulate the different kinds of receptors are not yet determined. There is no certainty as to the relation between total brightness and the brightness due to the individual receptors. Even such a mechanical process as the change in shape of the lens during accommodation is not beyond the sphere of active controversy, so it is not to be expected that the more recondite processes of visual perceptions will be agreed upon with equanimity.

The discussion was undoubtedly successful and a worthy successor to the one held a year ago on audition. With all the papers but one in print, the authors had only to refer to the salient points.

Unfortunately, Sir John Parsons was unable to attend and to open the proceedings. Mr. Guild undertook that duty at the eleventh hour, hence his opening remarks were not in print. From what one can recollect of them, the printed paper will be a valuable contribution to the philosophy of vision and a guide to future makers of hypotheses. All those interested in vision will look forward to the publication of the discussion in full.

\title{
Research Defence and Anti-Vivisection
}

TTHE Research Defence Society was founded in 1908 1 by the late Stephen Paget. It was the outcome of the Association for the Advancement of Medicine by Research and Prof. Starling's Committee which collected and presented evidence for medical and scientific research before the Royal Commission on Vivisection which sat in 1906-8. That Commission probed the anti-vivisection question to the depths, but declared in favour of research work under the Act of 1876 , which has controlled the use of animals for experimental purposes in England for more than half a century. In spite of this rebuff, anti-vivisectionists have continued to attack research workers and their institutions, even those who are engaged on veterinary research. The Research Defence Society undertook to inform the public of the conditions under which animals are used, the need for the work, and the alleviation of human and animal suffering which has resulted from such work.

The Annual Report of the Society for the past year pays a glowing tribute to the work and devotion of the late Lord Knutsford, who had been chairman since 1908. The Hon. Sir Arthur Stanley, chairman of the British Red Cross Society, succeeds Lord Knutsford as chairman of Committee, and.Prof. A. V. Hill has accepted the office of vice-chairman formerly held by Mr. Stephen Paget, while the following have become vice-presidents of the Society : Mary Viscountess Knutsford, Mrs. F. M. Sandwith, Lord Moynihan, Sir Frederick Gowland Hopkins, Sir Walter Fletcher, Sir Alfred Beit, Sir Henry H. Dale.

During the year under review, an event of outstanding importance was the final judgment of the Court of Appeal and the Order of the House of Lords in regard to the will of the late Mrs. Sarah Martha Grove-Grady, who left her residuary estate, amounting to approximately $£ 200,000$, to found and endow a new anti-vivisection organisation. If this bequest had been held to be charitable, a slur would have been cast on medical and veterinary progress by research and on institutions registered under the Act of 1876, for the conditions she laid down even precluded the Royal Society for the Prevention of Cruelty to Animals from accepting any of her money, because it could not be said that all members of the governing body of that Society were confirmed anti-vivisectionists. Largely as a result of the endeavours of the Research Defence Society, the Court of Appeal reversed the decision of a lower court which had upheld the will, and an Order of the House of Lords finally settled the case by ruling that $£ 25,000$ out of the residuary estate should be devoted to the benefit of animals, provided that none of the money were used for anti-vivisection propaganda. The Research Defence Society urged that this money should be given to the Royal Veterinary College (which had been attacked by anti-vivisectionists), with the gratifying result that the whole of the sum has now been allocated to that institution for the purposes of building and endowing an animals' hospital.

The annual general meeting of the Society took place on June 3, in the lecture hall of the London School of Hygiene and Tropical Medicine. Lord Lamington, the president, took the chair, and Sir Arthur Keith delivered the sixth Stephen Paget Memorial Lecture on "Some Aspects of the Modern Conflict between Sentiment and Reason".

Sir Arthur opened by contrasting physical and

No. 3269, VoL. 129] 
physiological research, pointing out that whereas the physicist has to satisfy only a scientific ideal, the physiologist has to confront an ethical as well as a scientific standard. "The conflict between sentiment and reason, as carried on to-day, finds its sharpest expression in the opposition offered to the beneficial work carried on by experimental physiologists. This society-the Research Defence Society-rightly concentrates its efforts on the vindication of the work carried on in our physiological laboratories. The antivivisection crusade is dangerous and has to be repelled, but after all, it is only an acute manifestation of a conflict which permeates modern society - a conflict in which blind sentiment is ranged against clear reason."

In dealing with the conflict between economic needs and sentiment, Sir Arthur pointed out the difference in the conditions when our ancestors hunted for their food and modern times when animals are deliberately bred for the butcher. We have to recognise by force of reason our economic needs, or, if sentiment becomes too strong, we must forswear all forms of animal meat. He continued: "It is not sentiment but reason which must be the final arbiter in the attitude we are to adopt to our four-footed dumb friends".

Discussing the problem of cruelty, Sir Arthur said: "The vice of cruelty has been given to man for the same reason as a sting has been given to the wasp and thorns to the rose-namely, for protection-to make their enemies afraid of them ". In its primitive form it is a vice of hot blood ; thoughtless cruelty, on the other hand, is a prevalent failing which everyone would wish to see eliminated. The most terrible form of cruelty is that which wilfully seeks to misinterpret motive. While there is need for a society to save animals from unnecessary suffering, there is still more need for a society, such as the Research Defence Society, to save scientific men from the cruelty of misrepresentation and of injustice.

Critics of research on animals have based arguments on so-called common sense, but as Sir Arthur pointed out: "When 'common sense' comes against expert knowledge, retreat is the wiser policy. Darwin's victory was one over the 'common sense' of his age. In the recondite fields of medicine, especially in the basal science of physiology, we must be prepared to be guided not by common sense but by the argument of irrefutable fact. We can hardly expect the man in the street, who has his own preoccupations, to know all that special experience has vouchsafed to us. If research is to prosper, the great public must be kept informed of its aims and accomplishments."

Sir Arthur then paid an eloquent tribute to the work for animals carried out by the Royal Veterinary College, and condemned emphatically the anti-vivisectionists who had attempted to frustrate the appeal of that institution for funds.

\section{University and Educational Intelligence}

Birmingham.-Applications from holders of an honours degree in engineering of a British university are invited for the James Watt Research Fellowship in Mechanical Engineering, the annual value of which is about $£ 250$. They should reach the Registrar of the University by, at latest, July 11.

CAmbridge.-The John Humphrey Plummer professorship of inorganic chemistry has been established, and the electors will meet on July 18. The stipend of the professor is $£ 1200$ a year or, if he holds a fellowship with dividend, $£ 1000$ a year. Candidates are requested to communicate with the Vice-Chancellor on or before July 7 .
Applications for the Gwynaeth Pretty Studentship, the holder of which shall devote himself to original research in the etiology, pathology, and treatment of disease, with particular but not exclusive reference to those diseases which cripple or disable in childhood or early life, are invited, and should be sent before July 30 to Prof. H. R. Dean, Department of Pathology. The studentship is of the annual value of $£ 200$ and is tenable for three years.

The Lucasian professorship of mathematics will be vacated by Sir Joseph Larmor on Sept. 30. A meeting of the electors will be held on July 25. The stipend of the professor is $£ 1200$ a year or, while the professor holds a fellowship of a college with dividend, $£ 1000$. Candidates for the professorship are requested to communicate with the Vice-Chancellor on or before July 11.

Dr. W. H. Thorpe, of Jesus College, has been appointed University lecturer in entomology. Mr. B. H. C. Matthews, of King's College, has been appointed assistant director of physiological research.

Applications are invited by the Royal College of Physicians of London for two Leverhulme research scholarships, each of the annual value of $£ 500$, for the investigation of some clinical problem of disease as it occurs in man. Applications must be sent before July 4 to the Registrar, Royal College of Physicians, Pall Mall East, S.W.1.

The Science Scholarships Committee of the Royal Commission for the Exhibition of 1851 has made the following appointments to Senior Studentships for 1932, the name of the recommending university being given in brackets: Dr. S. Tolansky (Durham), for research in physics; Mr. R. S. Alcock (Cambridge), for research in biochemistry; $\mathrm{Mr}$. S. H. Bastow (Cambridge), for research in physical chemistry ; $\mathrm{Mr}$. H. D. Ursell (Cambridge), for research in mathematics; Dr. E. A. Moelwyn-Hughes (Oxford), for research in physical chemistry; Dr. R. D. Preston (Leeds), for research in botany.

Elementary education in the United States of America is reviewed in Bulletin No. 20, 1931, of the Office of Education, Washington, consisting of advance pages of the official biennial survey for 19281930. Widespread appreciation of the conception of learning as an active rather than an absorptive process has led to notable improvements in equipment, courses, and instructional materials providing for constructing, illustrating, dramatising, modelling, and many other formas of creative activity. Elementary school aims have shown progressive enlargement of scope so as to include, in addition to the traditional function of instruction, the promotion of physical, recreational, educational, and social welfare outside the regular school day, as is evidenced by the creation of new posts such as home visitor, social care worker, after-school recreational director, and director of parent educational activities, and also by the linking up of school work with libraries, clubs, juvenile courts, Red Cross works, and community clinics. The instructional possibilities of radio and sound films have been receiving close attention. There has been a movement towards requiring a certain minimum standard of special qualifications when selecting school librarians, teachers of elementary school science, literature, and social studies. Finally, much ingenuity has been devoted to the elaboration of courses of study for pupils of different learning, interests, difficulties, or capacities. 